\title{
Does classical eyeblink conditioning generate sensitization of the neural pathway of the conditional stimulus (CS+)?
}

\author{
MAGNE ARVE FLATEN and KENNETH HUGDAHL \\ University of Bergen, Bergen, Norway
}

\begin{abstract}
The present experiment was designed to investigate the hypothesis that classical eyeblink conditioning in humans generates sensitization of the neural pathway of the reinforced conditional stimulus (CS+). The method of startle-reflex modification was used to index sensitization. Three groups $(n=20)$ received $100 \%, 50 \%$, and $10 \%$ differential reinforcement of an auditory $\mathrm{CS}+$, while the CS - was never reinforced. The reinforcer was an airpuff to the eye, presented 865 msec after CS + onset. After 20 conditioning trials, startle-eliciting noise was presented at different intervals after onset of the CS+ and CS-, and startle-reflex facilitation was used as an index of sensitization. Differential conditioning was observed only in the group that received $100 \%$ reinforcement. Startle-reflex facilitation was observed after onset of the CS+ in the group that received $100 \%$ reinforcement, whereas no difference was observed between startle reflexes elicited during the CS + and CS - in the other groups. The results indicate that startle-reflex facilitation is caused by sensitization of a specific neural pathway, and that startle-reflex facilitation is an indicator of neural sensitization in humans.
\end{abstract}

The present experiment was carried out to investigate whether classical conditioning in humans induces differential sensitization of the neural pathway of the reinforced conditional stimulus $(\mathrm{CS}+)$. This was done by investigating whether the startle reflex was facilitated when it was elicited by a startle-eliciting stimulus (i.e., a startle probe) presented after onset of the $\mathrm{CS}+$, as compared with the startle reflex elicited after onset of the nonreinforced CS-.

Flaten and Hugdahl (1990a) found startle-reflex facilitation to an acoustic startle probe when the probe was presented at different stimulus onset asynchronies (SOAs) after onset of an acoustic prestimulus that preceded an airpuff to the eye. However, reduced startle reflexes were elicited when the probe was presented concomitant with a stimulus that did not precede the airpuff. The stimulus that preceded the airpuff is formally a reinforced CS +, and it was hypothesized that the startle-reflex facilitation observed during this stimulus indicated sensitization of the neural pathway of the CS+.

The concept of sensitization as used here is derived from the work of Kandel and his associates on the neural basis of sensitization and classical conditioning (Abrams \& Kandel, 1988; Hawkins, Abrams, Carew, \& Kandel, 1983; Hawkins \& Kandel, 1984). Sensitization involves an increase in excitability of the sensory neurons stimu-

\footnotetext{
The present study was financially supported by grants from the Norwegian Council for Research in the Social Sciences (NAVF-RSF) and Nansenfondet to Magne Arve Flaten. Address all communications to Magne Arve Flaten, Department of Biological and Medical Psychology, Division of Somatic Psychology, Aarstadveien 21, N-5009 Bergen, Norway. E-mail address: MAGNE.FLATEN@ESUIT.UIT.NO.
}

lated by an aversive unconditional stimulus (US) (Hawkins \& Kandel, 1984; Thompson, Donegan, \& Lavond, 1988). This occurs most likely through presynaptic facilitation produced by interneurons that act on the stimulated sensory neurons. The sensitization procedure also results in increased excitability of several reflexes besides the one originally sensitized (Hawkins \& Kandel, 1984), implying that sensitization is a nonspecific process much like arousal.

Classical conditioning may be thought of as differentiation of sensitization. The effects of the conditioning procedure are specific, and the result is an increase only in responses to stimuli that are paired with the US. This specificity or differentiation of sensitization comes about through the mechanism of activity-dependent amplification of presynaptic facilitation (Hawkins et al., 1983). In classical conditioning, the relevant $\mathrm{CS}+$ neurons are activated immediately before the activation of the neurons conducting the US. The activated US neurons activates the unconditional response (UR) pathway, and in addition facilitates the synaptic potential of the sensory neurons conducting the $\mathrm{CS}+$, through facilitator interneurons from the US pathway to the CS + pathway. Only sensory neurons activated immediately before the pathway of the US is activated receive such excitatory input from the US neurons. Thus, the CS - pathway is not sensitized.

Sensitization of a specific neural pathway is an explanation of a form of conditioning in which the CS elicits the to-be-conditional response (CR) before conditioning (Thompson et al., 1988). This should make it suitable in the study of human eyeblink conditioning, since the CSs often elicit eyeblinks prior to conditioning. 
A sensitized neural pathway is more easily activated by $\mathrm{CS}+$ presentations than a pathway that is not sensitized. When the neural pathway of the CS + is activated by CS+ presentations, the eyeblink motor neurons have a higher probability of being activated, or are more strongly activated, after pairings of the CS + and US than before such pairings.

In the present experiment, three groups of subjects received $100 \%, 50 \%$, or $10 \%$ reinforcement of the CS +, while the CS - was never reinforced. It was hypothesized that this would generate different degrees of sensitization in the sensory neurons of the CSs, with the most sensitization in the CS + neurons in the group that received $100 \%$ reinforcement and the least in the CS - neurons. The US was an airpuff to the eye. After the conditioning phase, the CS + and CS - were presented at different SOAs before the presentation of startle-eliciting white noise (i.e., the startle probe).

It was hypothesized that the reflex magnitudes elicited by the startle probe that was presented when the neural pathways of the CS + and CS - were activated should indicate the degree of sensitization of these neural pathways. When the neural pathway of the CS + was activated, this should increase the activation of the eyeblink motor pathway, so that presenting the startle probe after onset of the CS + should increase eyeblink magnitudes, as compared with when the same stimulus was presented after the CS -.

This method is called startle-reflex modification, and the logic for its use here is as follows: The startle probe elicits an eyeblink, which means that the motor pathway of the startle reflex is the same as the eyeblink motor pathway of the CS tones and US airpuff used in the present study. It has been argued that presentations of the CS + will increase activation in the pathway conducting this stimulus, because the pathway has been sensitized by activity-dependent amplification of presynaptic facilitation. If the sensitized CS + pathway is activated by a presentation of the CS + , it will activate the eyeblink motor pathway more than a presentation of the CS - will. Consequently, when a startle probe is presented after CS+ onset, the eyeblink motor pathway, which is common to the $\mathrm{CR}$ and the startle reflex, will already be activated to some degree, and the startle probe will elicit an eyeblink that is larger than it would be if the startle probe was presented after CS - onset. In this way, one may index the degree of activation of a sensory pathway by observing its facilitatory effect on the motor neurons of a reflex.

The process of activating motor neurons by weak prestimuli, and thereafter presenting reflex-eliciting stimuli to test for activation is also called "conditioning" of a motoneuron pool (Brunia \& Boelhouwer, 1988).

The aim in the present experiment was to investigate whether sensitization was stimulus-specific, or whether it involved generalized arousal induced by the US. It was hypothesized that if sensitization is stimulus-specificthat is, if there is more sensitization of the CS + pathway than of the CS - pathway - then the degree of sensitization should be an increasing function of the reinforcement schedule, with $100 \%$ reinforcement of the CS + yielding maximal sensitization, as indexed by increased startle reflexes elicited after CS + onset in Group 100.

Startle probes (noise) were presented at different SOAs after onset of the CS + and CS-. This was done to investigate whether the sensitized neural pathway would increase its activating output as a function of time after CS + onset, or whether it would remain stable across the different SOAs.

\section{METHOD}

\section{Subjects}

Sixty students at the University of Bergen, 23 males and 37 females, participated in the experiment. An additional 9 subjects were discarded because they did not meet the criterion of displaying at least $20 \%$ trials with observable startle reflexes in the reflex modification phase.

\section{Apparatus and Stimuli}

The experiment was run in a sound-attenuated chamber inside the laboratory. Temperature and light conditions were constant for all subjects during the experiment.

Eyeblink reflexes were detected by a photocell (TIL 32) as changes in light reflection from the eye and eyelid. Degree of voltage emitted from the photocell indicated degree of closure of the eyelid (see Flaten, Vaksdal, \& Hugdahl, 1989, for details). A similar apparatus for recording eyeblinks has been employed by Anday, Cohen, Kelley, and Hoffman (1988), who reported that it compared favorably with the more commonly employed potentiometer. Blinks were sampled at $250 \mathrm{~Hz}$ at the right eye for $1.5 \mathrm{sec}$ after signal stimulus onset.

Skin conductance levels (SCLs) were recorded by a Beckman Type RS Dynograph with the help of a Beckman Type 9844 Skin Conductance Coupler. Beckman $\mathrm{Ag} / \mathrm{AgCl}$ cup electrodes with a diameter of $8 \mathrm{~mm}$ were used. NASA electrode paste was used as the electrode medium. However, since no significant differences were found between the groups in SCLs, these data are omitted.

Tones and noise were generated by a Commodore 64 microcomputer. Tones (i.e., the conditional stimuli) had frequencies of 330 and $530 \mathrm{~Hz}$ at $94 \mathrm{~dB}$, with a duration of $1,400 \mathrm{msec}$. The CS durations were longer than the CS+/US interstimulus interval (ISI of $865 \mathrm{msec}$ ) in order that the CSs should be heard at all SOAs in the reflex modification phase. Noise (i.e., the startle probe) was white noise at $97 \mathrm{~dB}$, with a rise time of $8 \mathrm{msec}$ and a duration of $240 \mathrm{msec}$. Startle probes were presented at $220,380,1,080$, and $1,260 \mathrm{msec}$ after onset of the conditional stimuli in the reflex modification phase. Background noise at 60-69 dB was delivered through the same loudspeaker as the tone and noise stimuli. The auditory stimuli were measured by a Brüel and Kjaer Sound Precision Meter. The auditory stimuli were amplified by a NAD $3220 \mathrm{~B}$ stereo amplifier and fed to a Beovox CX 50 loudspeaker placed about $40 \mathrm{~cm}$ behind and above the head of the subject.

Airpuffs were delivered to the right eye; they were at $1.8 \mathrm{psi}$ at the mouth of the air nozzle placed 3-4 cm from the subject's eye. The duration of each puff was $100 \mathrm{msec}$, as controlled by a solenoid valve placed outside of the experimental chamber.

\section{Procedure}

The experiment consisted of three phases.

Habituation. Each subject received three presentations of the tobe $\mathrm{CS}+$ and to-be $\mathrm{CS}-$. This was done to habituate orienting or alpha responses elicited by the stimuli.

Differential conditioning. This phase involved a delay conditioning procedure that followed immediately after the habituation phase. 
Group 100 received presentations of the tone $(\mathrm{CS}+) 865 \mathrm{msec}$ before presentations of the airpuff (US) according to a $100 \%$ reinforcement schedule.

Group 50 had a $50 \%$ reinforcement schedule, with $50 \%$ of the CS + presentations followed after $865 \mathrm{msec}$ by the US, and $50 \%$ of the US presentations not preceded by any CS.

Group 10 had a $10 \%$ reinforcement schedule with $10 \%$ of CS + presentations followed after $865 \mathrm{msec}$ by the US, $90 \%$ of the CS + presentations not followed by the US, and $90 \%$ of the US presentations not preceded by any CS.

The CS - was never paired with the US in any group.

All groups received 20 presentations each of the CS,$+ C S-$, and US. Each tone had a duration of $1,400 \mathrm{msec}$. Which tone was used as the CS+ or CS - was counterbalanced across subjects within each group.

The $20 \mathrm{CS}+$ and $20 \mathrm{CS}-$ trials were analyzed in blocks of five trials.

To enhance discriminability between stimuli, massed presentations of the stimuli were used, so that the CS + and CS - were presented in series of between 2 and 5 stimulus presentations in Groups 50 and 10 , and between 5 and 10 stimulus presentations in Group 100 . This means, for example, that Group 100 first received 5 consecutive presentations of the $\mathrm{CS}+$, then the $\mathrm{CS}-5$ times, then the $C S+10$ times, then the $C S-10$ times, then the $C S+5$ times, and then the $C S-5$ times. Groups 50 and 10 received $C S+s, C S-s$, and USs in series that contained from 2 to 5 consecutive stimulus presentations.

Reflex modification. This phase followed immediately after the conditioning phase. Each group was divided into two subgroups $(n=10)$ with startle probes presented at SOAs of $220,380,1,080$, or $1,260 \mathrm{msec}$ after onset of the CS + in one subgroup, and after onset of the CS - in the other subgroup. The conditioning groups were subdivided into subgroups to avoid the presentation of both the CS + and the CS - to the same subject, because too many pairings of the CSs and the startle probe could extinguish the eyeblink conditioning. The startle probes were also presented alone as the first and last stimuli in this phase. The SOAs were identical to those used in Flaten and Hugdahl (1990a); they were well suited for the present experiment, since the startle probe was presented at times when there was little chance of any confusion with the CR (Donegan \& Wagner, 1987), which was hypothesized to occur from about $300 \mathrm{msec}$ after CS + onset until US onset at $865 \mathrm{msec}$. The CR may also be topographically different from the startle-reflex response (see Figure 1), which can make it easier for one to differentiate between startle and CRs.

The presentation order of the different SOAs was counterbalanced within each group.

\section{Design}

The design for the differential conditioning phase was 3 (groups: 100,50 , and 10) $\times 2$ (stimuli: CS + and CS - ) $\times 4$ (trial blocks). The group factor was treated as a between-groups factor, and the stimuli and trial blocks factors were treated as within-groups factors with repeated measures.

The design for the reflex modification phase was 2 (groups: 100 and 50/10) $\times 2$ (stimuli: $\mathrm{CS}+$ and CS - ) $\times 5$ (SOA: S2-alone, $220,380,1,080$, and $1,260 \mathrm{msec}$ ), with the two first factors treated as between-groups factors, and the SOA factor treated as a withingroups factor with repeated measures. Groups 50 and 10 were collapsed into one group because no differential conditioning was observed in these groups.

\section{Data Analysis}

Eyeblink amplitudes were scored as the difference between the resting level immediately before the eyeblink, and the maximal amount of reflection measured when the subject's right eye blinked. Each score was range-corrected according to Lykken (1972), with

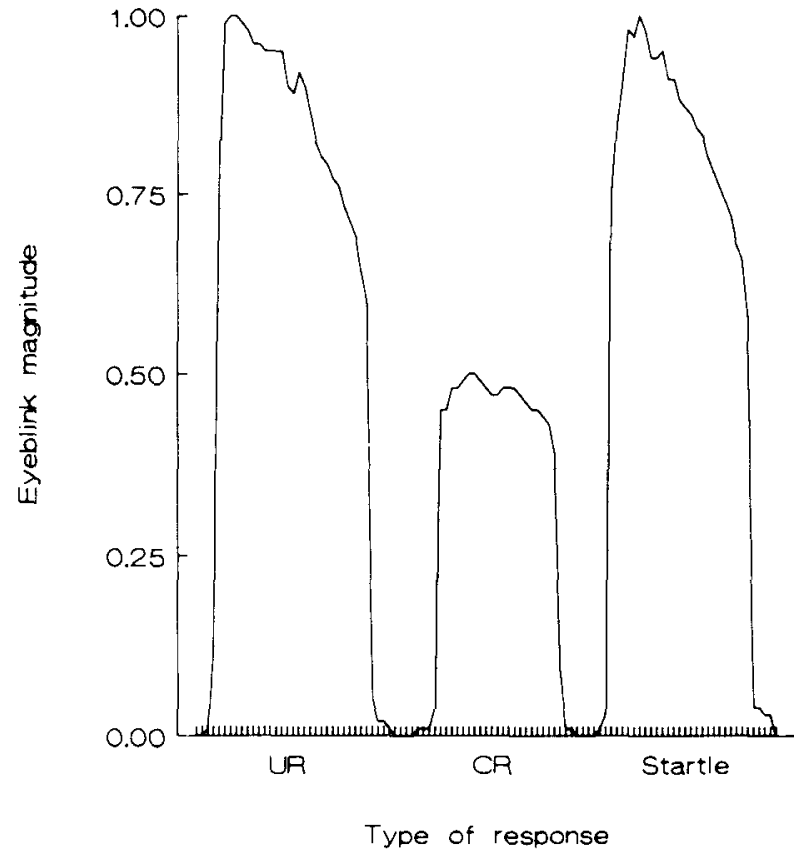

Figure 1. Examples of, from left to right, an unconditional eyeblink response (UR) elicited by an airpuff to the eye, a conditional eyeblink response (CR) elicited by a tone paired with an airpurf, and an eyeblink startle reflex elicited by an acoustic startle probe at $100 \mathrm{~dB}$.

each individual response divided by that subject's largest response. This yields a ratio score between zero (no response) and 1.00 (maximum response).

Response probability was also computed in the reflex modification, since the magnitude measure may be a compound measure of probability and amplitude (cf. Blumenthal \& Berg, 1986).

\section{Statistical Analyses}

Eyeblink magnitudes were subjected to overall analysis of variance (ANOVA). The factors containing repeated measures were corrected according to Hand and Taylor (1987); the degrees of freedom for the numerator and denominator mean squares were divided by the degrees of freedom for the repeated measures factor. Theoretically interesting differences were followed up with contrast analyses (Rosenthal \& Rosnow, 1986).

\section{RESULTS}

\section{Eyeblink Conditioning}

Mean eyeblink CR magnitudes can be seen in Figure 2.

There was a significant main effect of stimulus $[F(1,57)$ $\left.=21.11, M S_{\mathrm{e}}=.0325, p<.01\right]$, due to stronger responding to the $\mathrm{CS}+$. Furthermore, there was a significant interaction of groups $\times$ stimulus $[F(2,57)=$ $\left.11.87, M S_{e}=.0325, p<.01\right]$.

The significant interaction of groups $\times$ stimulus was followed up with contrast analyses. These showed significantly stronger responding to the $\mathrm{CS}+$ than to the $\mathrm{CS}-$ in Group $100\left[F(1,33)=12.21, M S_{\mathrm{e}}=.0325, p<.01\right]$. There were no significant corresponding differences in Groups 50 and $10\left(F_{s}<1\right)$. Groups 50 and 10 were 


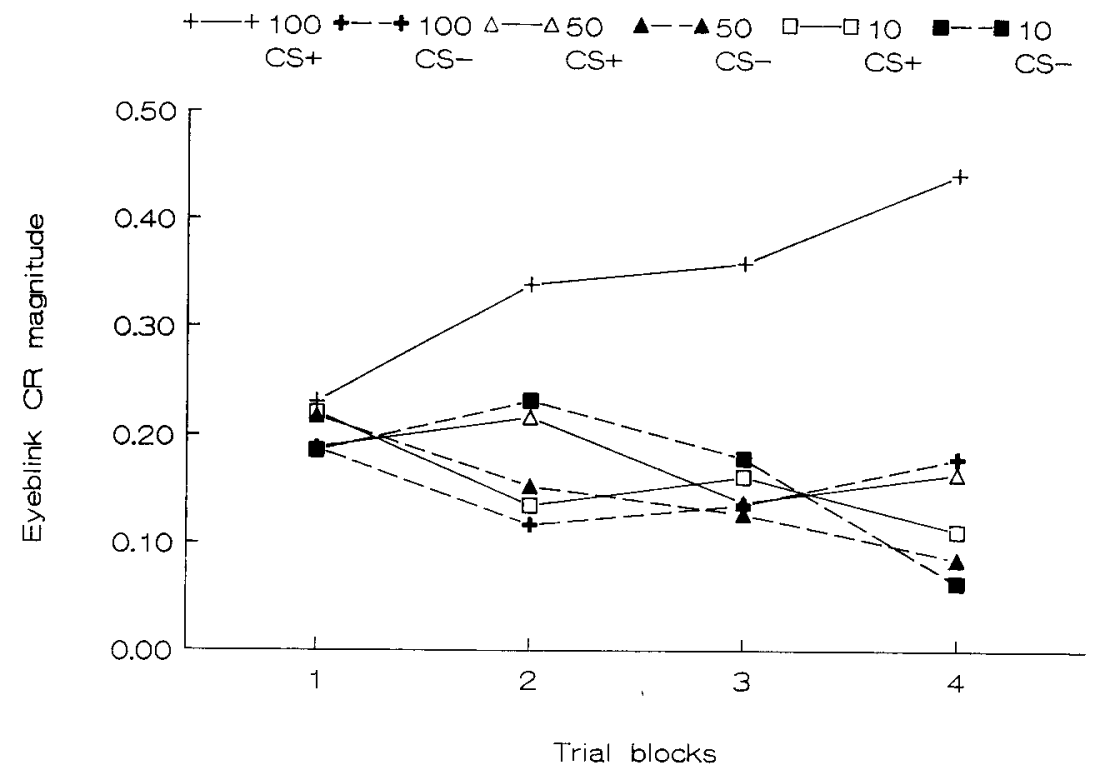

Figure 2. Mean range transformed eyeblink conditional response (CR) magnitudes for each group and stimulus during differential eyeblink conditioning. Each trial block consists of five trials. The numbers 100,50 , and 10 indicate Groups 100,50 , and 10 , respectively.

therefore collapsed in the data analyses for the reflex modification phase.

\section{Reflex Modification}

Mean startle reflexes can be seen in Figure 3.

There was a significant main effect of stimulus $[F(1,56)$ $\left.=5.91, M S_{\mathrm{e}}=.3433, p<.05\right]$, due to larger responses to the startle probe during the $\mathrm{CS}+$. There was also a significant main effect of SOA $\left[F(1,56)=13.07, M S_{\mathrm{e}}=\right.$
$.1101, p<.01]$. Figure 3 indicates that this was due to larger responses at the longer SOAs.

There was a marginally significant interaction of groups $\times$ stimulus $\left[F(1,56)=3.01, M S_{\mathrm{e}}=.3433, p=.084\right]$, due to increased responding to the $\mathrm{CS}+$ as compared with the CS - in Group 100.

Finally, there was a significant interaction of stimulus $\times \operatorname{SOA}\left[F(1,56)=4.98, M S_{\mathrm{e}}=.1101, p<.05\right]$, due to stronger responding at longer SOAs during the CS+.

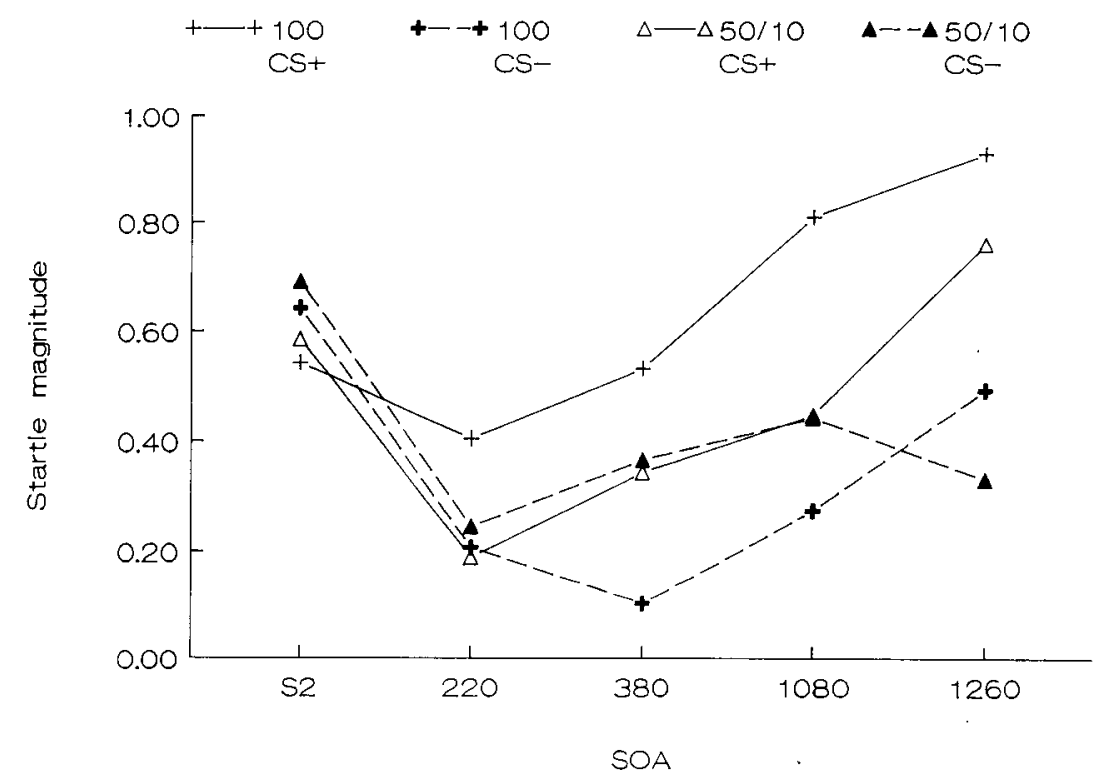

Figure 3. Mean range transformed startle-reflex magnitudes elicited in each group after onset of the CS + and CS - across stimulus onset asynchronies (SOAs) in the reflex modification phase. Presentations of the acoustic startle probe alone is denoted S2. 
No other main effects or interactions were significant.

Differences between means for significant sources of variation were evaluated by contrast analyses. There were significantly stronger reflex responses to the startle probe during the $\mathrm{CS}+$ as compared with the CS - in Group 100 $\left[F(1,56)=8.53, M S_{e}=.3732, p<.01\right]$. There was no difference between the CS + and the CS - in Group 50/10 $(F<1)$. The difference in responding to the startle probe during the CS + between Groups 100 and $50 / 10$ was only marginally significant $\left[F(1,56)=3.89, M S_{\mathrm{e}}=.3732\right.$, $p=.0505]$.

The difference between the CS+ and the CS - in Group 100 occurred at $380 \mathrm{msec}\left[F(1,56)=5.49, M S_{\mathrm{e}}=\right.$ $.1671, p<.025]$, at $1,080 \mathrm{msec}\left[F(1,56)=7.95, M S_{\mathrm{e}}\right.$ $=.1808, p<.01]$, and at $1,260 \mathrm{msec}[F(1,56)=5.81$, $\left.M S_{\mathrm{e}}=.1631, p<.025\right]$. This indicates that the difference in responding during the CS + and $C S-$ in Group 100 was relatively stable across SOAs.

Reflex facilitation was observed in Group 100 only at 1,260 msec after CS + onset, when compared with the reflexes elicited by the startle probe presented alone $\left[F(1,56)=4.69, M S_{e}=.1598, p<.05\right]$. Reflex inhibition was observed at $220 \mathrm{msec}$ in Group 50/10 during both the CS + and CS -, compared to the reflex elicited by the startle-eliciting stimulus alone, whereas reflex inhibition was only observed during the CS - in Group 100; the CS + in Group 50/10 $\left[F(1,56)=12.60, M S_{\mathrm{e}}=.1247\right.$, $p<.01]$; the CS - in Group $50 / 10[F(1,56)=15.91$, $\left.M S_{\mathrm{e}}=.1247, p<.01\right]$; the CS + in Group $100(F<1)$; and the CS - in Group $100\left[F(1,56)=7.58, M S_{e}=\right.$ $.1247, p<.01]$.

Thus, reflex facilitation was observed during the CS+ in Group 100, both relative to the reflexes elicited in the other groups, and relative to the reflexes elicited by the startle probe alone.

\section{DISCUSSION}

Differential conditioning was established only in Group 100 during the conditioning phase. It was therefore hypothesized that only the neural pathway of the CS+ in Group 100 was sensitized.

The startle data confirmed this. They revealed stronger responding to the $\mathrm{CS}+$ compared to the $\mathrm{CS}-$ in Group 100 . This difference was relatively stable across the 380-, 1,080-, and 1,260-msec SOAs, indicating that the degree of activation of the motor pathway of the eyeblink, by the sensitized CS + pathway, was constant across the different SOAs. The lack of a significant difference at $220 \mathrm{msec}$ may be explained by failure of discrimination between the CS + and CS - at such a short SOA.

There was no difference between the groups during the CS -, indicating that the sensitization in the CS + pathway in Group 100 did not influence the stimulus processing that took place during the $\mathrm{CS}$-.

Two possibly contaminating sources of variance should be discussed before further interpretation of the results. It could be argued that the CS + in Group 100 elicits con- ditional excitation at the facial nucleus, thus increasing startle reflexes elicited after the CS + . However, excitation of the facial nucleus should activate the orbicularis oculi, and this should be observed as partial closure of the eyelid after CS + presentations in Group 100. The data do not show an increased "baseline" of eyelid closure after CS + onset in Group 100, and it may be concluded that conditional excitation at the facial nucleus did not cause the present increased startle reflexes after CS + onset in Group 100. In addition, it is not clear that conditional excitation at the facial nucleus should increase startle reflexes, since the law of initial values predicts the opposite result because of higher physiological activation in the conditional excitation state.

It could also be argued that what is observed in the reflex modification phase is reduced startle reflexes after onset of the CS + and CS - in Group 50/10, and after the CS - in Group 100. Thus, startle-reflex inhibition rather than facilitation is observed, and consequently the results may be explained by neural inhibition, for example, instead of sensitization. However, this argument cannot be accepted for two reasons: First, startle-reflex facilitation is observed at $1,260 \mathrm{msec}$ after CS + onset in Group 100, compared to reflexes elicited by the startle probe alone. This comparison yields a measure of sensitization that is independent of inhibition in the neural pathways of the $\mathrm{CS}+\mathrm{s}$ and $\mathrm{CS}-\mathrm{s}$ in Group 50/10. Second, there should be different degrees of inhibition in the different CS pathways in the other groups, with most inhibition in the CS pathways and least inhibition in the CS + pathway in Group 50/10. Figure 3 shows a tendency for smaller startle reflexes-after the CS - in Group 100 . However, the effect is found only at 380 and $1,080 \mathrm{msec}$, and it is not statistically significant. Consequently, the increased startle reflexes after CS + onset in Group 100 can be interpreted as evidence of neural sensitization, and any effects of inhibition in the present experiment are weak.

Thus, the present results give support to the notion that Kandel's theory of classical conditioning (e.g., Hawkins \& Kandel, 1984) also may be applied to human conditioning, and, consequently, that human classical conditioning is a process that takes place in the sensory part of the reflex arc.

It may be that only a smaller part of the pathway of the CS + is sensitized. This could, for example, be a pathway from a memory of the $\mathrm{CS}+$, to the eyeblink motor pathway. Thus, CS + presentations may activate the memory of the $\mathrm{CS}+$, which in turn would activate the neural pathway from the memory to the motor pathway. The present experiment does not allow us to differentiate between theories that specify where along the neural pathway of the CS + sensitization occurs. We have chosen temporarily to accept the simplest explanation of the present results, which is the theory put forth in the introduction.

Several authors (e.g., Anthony, 1985; Graham, 1975; Hoffman \& Ison, 1980) have argued that reflex modification of startle does not depend on learning, since the effect may be observed on the first trial of paired stimu- 
lation. Our present study does not necessarily refute this, but we have shown that reflex modification of startle may be facilitated by classical conditioning.

Previous work on the relationship between electrodermal reflex modification, classical conditioning, and habituation has shown that conditioning does not influence electrodermal reflex modification (e.g., Flaten \& Hugdahl, 1990b). However, electrodermal conditioning is transient and may be difficult to observe during acquisition; and procedural changes have a relatively strong influence on electrodermal reflex modification (Flaten \& Hugdahl, 1990c), which may overshadow any effects of conditioning.

Few previous studies have been done to investigate whether classical conditioning influences reflex modification of the eyeblink in humans. Ison and Ash (1977) found no evidence for any influences of classical conditioning when using five conditioning trials with a $50 \%$ reinforcement schedule. In the present study, we did not find any conditioning effects on reflex modification with 20 trials in a $50 \%$ reinforcement schedule.

Greenwald, Hamm, Bradley, and Lang (1988) performed a study that is closely related to the present one. Shock USs were paired with visual CS $+s$ during conditioning. After conditioning, startle-eliciting noise was presented during the CSs. The results showed stronger responding to the noise presented during the CS+ than to noise presented alone or during the CS -. Greenwald et al. (1988) interpreted this observation of startle-reflex facilitation in terms of a negative emotional response elicited by the CS +, which was added to the negative emotional response elicited by the startle probe, thus facilitating the startle reflex when the noise was presented during the CS + (see also Lang, Bradley, \& Cuthbert, 1990). Greenwald et al. (1988) hypothesized further that it was both the emotional valence and the intensity (or arousal) of the emotion that determined the magnitude of the startle reflex.

Davis, Schlesinger, and Sorenson (1989), Ross (1961), and Spence and Runquist (1958) observed similar results, but interpreted startle-reflex facilitation as the result of conditional fear elicited by the CS + .

The results from the present experiment can be interpreted as evidence for differential sensitization rather than arousal, conditional fear, or emotional valence, for the following reasons: (1) A fear conditioning procedure was not utilized in the present experiment. In earlier studies (Davis et al., 1989; Greenwald et al., 1988; Ross, 1961; Spence \& Runquist, 1958), a shock was used as the US, and the CS that signaled this was hypothesized to elicit a general process such as fear or arousal. The shock was chosen to be "unpleasant"' (Spence \& Runquist, 1958) or "definitely uncomfortable" (Ross, 1961). Contrary to this, in the present study we used a procedure that conditioned a specific reflex, and we used a US that was not aversive. (2) There was no differential increase in SCL in the subgroup of Group 100 that received the CS + in the reflex modification phase and showed facilitated reflexes. (3) All groups received the same number of airpuffs and noise stimuli and should therefore have displayed the same degree of arousal. (4) There were no differences between the groups in responding to the startleeliciting stimulus alone, as there should have been had there been different degrees of arousal in the groups. (5) Arousal or conditional fear is a general process affecting a large part of the central nervous system, and one could therefore expect this process to take some time to develop. Indeed, it has been concluded (Ross, 1961; Spence \& Runquist, 1958) that the latency of the conditional emotional response is longer than $500 \mathrm{msec}$, and that little fear conditioning takes place with a CS $+/ \mathrm{US}$ ISI of $500 \mathrm{msec}$ (the present study was done with an 865-msec CS +/US ISI). Greenwald et al. (1988) observed similar results. Opposite to this, Flaten and Hugdahl (1990a) observed a marginally significant difference after $220 \mathrm{msec}$, and in the present experiment the difference between the CS+ and CS - in Group 100 was significant after $380 \mathrm{msec}$. However, the conclusions of Spence and Ross have been challenged by Davis et al. (1989), who found that the latency of the conditional emotional response can be as short as $50 \mathrm{msec}$ in rats, depending on the CS+/US ISI used in fear conditioning.

These arguments support the notion that the process observed in the present experiment is specific to the neural pathway conducting the CS + in Group 100 , and that it is therefore not an instance of arousal or conditional fear.

The relationship between classical conditioning and reflex modification has been investigated in a few studies. Donegan (1981, Experiment 1) found an increased UR when the US was preceded by the CS + rather than the $\mathrm{CS}-$, but Donegan interpreted the increased responding to be the result of confusion of the CR with the UR elicited by the reflex-eliciting stimulus. However, this is most likely not the cause of the present results. First, it is not clear whether a confusion or an interaction of the $C R$ with the reflex response should increase reflex-response magnitude. Our own work on the SCR shows that an interaction of two responses inhibits the response to the second stimulus (Flaten \& Hugdahl, 1990b, 1990c). Second, reflex facilitation was largest at the two longest SOAs $(1,080$ and 1,260 msec), which were both longer than the ISI used in the conditioning phase ( $865 \mathrm{msec})$. Any CRs should therefore have occurred before the presentation of the startle probe and could therefore not have increased the startle reflex elicited at 1,080 and $1,260 \mathrm{msec}$. Third, startle reflexes were smallest at the $380-\mathrm{msec}$ SOA, the SOA that was inside the $300-865-\mathrm{msec}$ window in which CRs were hypothesized to occur. It could therefore seem as if CRs inhibit startle reflexes instead of facilitating them. Fourth, reflex facilitation is observed in the absence of any CRs (for reviews, see Anthony, 1985; Blumenthal \& Tolomeo, 1989).

It can be concluded that (1) the process that facilitates startle is specific to CSs that have been reinforced by USs and does not occur in response to nonreinforced CSs, and (2) the process is observed at $380 \mathrm{msec}$ after CS + onset 
and does not increase in strength at later SOAs, indicating that it is the result of a stable state in the neural pathway of the CS + . Since the process is specific and stable, we propose that it can be understood best as differential sensitization. According to animal studies (Hawkins et al., 1983; Hawkins \& Kandel, 1984), the neural basis for classical conditioning may be such differential sensitization of the CS+ pathway in the brain. If this is the case, the reflex modification method has possible relevance for noninvasive studies of processes underlying behavioral plasticity in humans.

\section{REFERENCES}

Abrams, T. W., \& Kandel, E. R. (1988). Is contiguity detection in classical conditioning a system or a cellular property? Learning in aplysia suggests a possible molecular site. Trends in Neurosciences, 11, 128-135.

Anday, E. K., Cohen, M. E., Kelley, N. E., \& Hoffman, H. S. (1988). Reflex modification audiometry: Assessment of acoustic sensory processing in the term neonate. Pediatric Research, 23, 357-363.

ANTHONY, B. J. (1985). In the blink of an eye: Implications of reflex modification for information processing. In P. K. Ackles, J. R. Jennings, \& M. G. H. Coles (Eds.), Advances in psychophysiology (Vol. 1, pp. 168-218). Greenwich, CT: JAI Press.

Blumenthal, T. D., \& Berg, W. K. (1986). Stimulus rise time, intensity, and bandwith effects on acoustic startle amplitude and probability. Psychophysiology, 23, 635-641.

Blumenthal, T. D., \& Tolomeo, E. A. (1989). Bidirectional influences of vibrotactile stimuli on modification of the human acoustic startle reflex. Psychobiology, 17, 315-322.

Brunia, C. H. M., \& BoelhouWer, A. J. W. (1988). Reflexes as a tool: A window in the central nervous system. In P. K. Ackles, J. R. Jennings, \& M. G. H. Coles (Eds.), Advances in psychophysiology (Vol. 3, pp. 1-67). Greenwich, CT: JAI Press.

Davis, M., Schlesinger, L. S., \& Sorenson, C. A. (1989). Temporal specificity of fear conditioning: Effects of different conditioned stimulus-unconditioned stimulus intervals on the fear-potentiated startle effect. Journal of Experimental Psychology: Animal Behavior Processes, 15, 295-310.

Donegan, N. H. (1981). Priming-produced facilitation or diminution of responding to a Pavlovian unconditioned stimulus. Journal of Experimental Psychology: Animal Behavior Processes, 4, 295-312.

Donegan, N. H., \& Wagner, A. R. (1987). Conditioned diminution and facilitation of the UR: A sometimes opponent-process interpretation. In I. Gormezano, W. F. Prokasy, \& R. F. Thompson (Eds.), Classical conditioning (3rd ed., pp. 339-369). London: Erlbaum.

Flaten, M. A., \& Hugdahl, K. (1990a). Effects of attentional de- mands and classical conditioning on startle-reflex facilitation. Manuscript submitted for publication.

Flaten, M. A., \& Hugdahl, K. (1990b). Effects of habituation and classical conditioning on reflex modification. International Journal of Psychophysiology, 9, 129-137.

Flaten, M. A., Hugdahl, K. (1990c). Reflex modification in the electrodermal system: Conceptual and methodological issues. Biological Psychology, 30, 3-12.

Flaten, M. A., Vaksdal, A., Hugdahl, K. (1989). An IBM PC and Commodore 64 microcomputer based system for elicitation and recording of the eyeblink reflex. Biological Psychology, 29, 291-298.

Graham, F. K. (1975). The more or less startling effects of weak prestimulation. Psychophysiology, 12, 238-248.

Greenwald, M. K., Hamm, A. O., Bradley, M. M., Lang, P. J. (1988). The acoustic startle probe in the assessment of classical aversive conditioning. Psychophysiology, 25, 451.

HAND, D. J., \& TAYLOR, C. C. (1987). Multivariate analysis of variance and repeated measures. London: Chapman \& Hall.

Hawkins, R. D., Abrams, T. W., Carew, T. J., Kandel, E. R. (1983). A cellular mechanism of classical conditioning in aplysia: Activity-dependent amplification of presynaptic facilitation. Science, 219, 400-405.

HawkIns, R. D., \& KANDEL, E. R. (1984). Is there a cell-biological alphabet for simple forms of learning? Psychological Review, 91, 375-391.

HofFMAN, H. S., \& Ison, J. R. (1980). Reflex modification in the domain of startle: 1 . Some empirical findings and their implications for how the nervous system processes sensory input. Psychological Review, 87, 175-189.

Ison, J. R., ASH, B. (1977). Effects of experience on stimulusproduced reflex inhibition in the human. Bulletin of the Psychonomic Society, 10, 467-468.

Lang, P. J., Bradley, M. M., \&uthbert, B. N. (1990). Emotion, attention, and the startle reflex. Psychological Review, 97, 377-395.

LYKKEN, D. T. (1972). Range correction applied to heart rate and to GSR data. Psychophysiology, 9, 373-382.

Rosenthal, R., Rosnow, R. L. (1986). Contrast analysis: Focused comparisons in the analysis of variance. London: Cambridge University Press.

Ross, L. E. (1961). Conditioned fear as a function of CS-UCS and probe stimulus intervals. Journal of Experimental Psychology, 61, 265-273.

SPENCE, K. W., \&UNQUIST, W. N. (1958). Temporal effects of conditioned fear on the eyelid reflex. Journal of Experimental Psychology, 55, 613-616.

Thompson, R. F., Donegan, N. H., \&avond, D. G. (1988). The psychobiology of learning and memory. In R. C. Atkinson, R. J. Herrnstein, G. Lindzey, \& R. D. Luce (Eds.), Stevens' handbook of experimental psychology (pp. 245-247). Chichester, U.K.: Wiley.

(Manuscript received February 21, 1990; revision accepted for publication June 5, 1990.) 